\title{
Factors associated with sleep quality of Thai intercity bus drivers
}

\author{
Jindarat CHAIARD ${ }^{1}$ *, Jirawan DEELUEA ${ }^{1}$, Benjamas SUKSATIT ${ }^{1}$ and Wanpen SONGKHAM ${ }^{1}$ \\ ${ }^{1}$ Faculty of Nursing, Chiang Mai University, Thailand \\ Received August 21, 2018 and accepted January 10, 2019 \\ Advanced Epub on J-STAGE January 25, 2019
}

\begin{abstract}
This study aimed to describe sleep quality and explore factors associated with poor sleep quality in Thai intercity bus drivers. A cross-sectional design was employed with a sample of intercity bus drivers from 4 bus transportation companies. The Thai-PSQI was used to identify sleep quality, and the Thai Berlin Questionnaire used to assess sleep apnea risk. Data analysis included descriptive statistics and logistic regression. A total of 338 surveys were analyzed. All bus drivers were male; almost $66 \%$ of the bus drivers were defined as poor sleepers, and $18.1 \%$ were assessed as being at high risk for obstructive sleep apnea. Working night shifts $(\mathrm{OR}=20.6)$, rotating day or night shifts $(\mathrm{OR}=17.0)$, alcohol consumption $(\mathrm{OR}=2.7)$, being married $(\mathrm{OR}=3.1)$, and not exercising $(\mathrm{OR}=2.3)$ were related to poor sleep quality. The majority of the Thai intercity bus drivers in our study reported poor sleep quality indicating that action is required at both company and individual levels to encourage the adoption of healthy lifestyles and improvement of working conditions.
\end{abstract}

Key words : Sleep quality, Sleep apnea, Bus drivers, Safety, Driving drowsy, Traffic crashes

\section{Introduction}

Sleep problems impact workers' health and pose an important public health concern. There is a growing awareness about the role of inadequate sleep and fatigue as the root cause of thousands of traffic crashes ${ }^{1)}$. Sleep quality is crucial among long-distance drivers and the research supported that good sleep quality resulted in a $62 \%$ reduction in cardiovascular risk ${ }^{2)}$. Drivers who slept less than $7 \mathrm{~h}$ and reported poor sleep quality were more fatigued than those with sufficient sleep ${ }^{3)}$. Drowsy driving has been found to be as dangerous as drunk driving because both drowsiness and alcohol impair driving ability, concentration and alertness, decision making, and delay reaction times ${ }^{4)}$. Fatigue-related accidents are complex and the

*To whom correspondence should be addressed. E-mail: jindarat.c@cmu.ac.th

(C)2019 National Institute of Occupational Safety and Health causes of fatigue include driving stresses; prolonged driving; insufficient sleep and sleep disorders; time of day and circadian variation; and motivation ${ }^{5)}$.

Prolonged driving produces fatigue and impairs driving's performance putting drivers at high risk to have traffic crashes. Fatigue is related to increased risk of inattention to traffic signs, a lack of awareness of safety behaviors, errors in dealing with the unexpected situation such as road conditions or other driver behaviors ${ }^{6}$. Drivers who fall asleep while driving may run off the road or into other cars or obstacles $^{7}$. Previous studies have shown that bus drivers in a number of countries experience drowsy driving, sleep problems, and low sleep quality ${ }^{8-10)}$. Drivers involved in crashes were shown to have poor sleep quality ${ }^{11)}$, shorter sleeping hours, and higher levels of excessive daytime sleepiness ${ }^{12}$. Fatigue, sleepiness, excessive speed, use of mobile phones, lapses, errors, and traffic violations were related to injuries from motor vehicle crashes among bus drivers in Turkey ${ }^{13)}$. Nearly three quarters (74\%) of bus drivers in Peru reported 
that while driving they experienced fatigue, $25 \%$ felt sleepy, and "nodding off" and these increase the risk of accidents or near accidents ${ }^{14)}$. In Thailand, $73.4 \%$ of bus drivers reported drowsy driving; although this study did not investigate associated accidents ${ }^{15}$. It is known that excessive daytime sleepiness resulting from sleep deprivation has a strong relationship with accidents ${ }^{16)}$.

Sleep quality in bus drivers may be affected by demographic characteristics, health status, and working conditions. Age, marital status, body mass index (BMI), disease and drug history are related to insomnia ${ }^{17)}$. Bus drivers have also been found to be at high risk for obstructive sleep apnea $(\mathrm{OSA})^{18,19)}$ and risk of OSA is associated with a low quality of sleep ${ }^{20)}$. When untreated, sleep apnea increases the risk of sleep-related traffic crashes because the sedentary nature of driving is likely to increase sleepiness ${ }^{21)}$. Working conditions such as evening and night work shifts and driving long hours each day have been found to be related to sleep disturbances ${ }^{22)}$. Unrealistic work schedules, less than $20 \mathrm{yr}$ of driving experience, and low job satisfaction have also been associated with poor sleep quality ${ }^{20)}$.

The World Health Organization (WHO) reported that Thailand had the second-highest number of traffic deaths in the world and about $1 \%$ involved the death of bus drivers and their passengers ${ }^{23}$. Public bus transportation is a major form of public transport both within and between cities in Thailand. In this paper, we have used the term "bus drivers" to refer to drivers who drive between cities rather than local bus drivers. These are referred in other studies as coach drivers or highway drivers. Many bus journeys are overnight posing additional sleep challenges for drivers. However, little information is available about sleep quality and related factors in intercity bus drivers in Thailand. Similarly, the risk of OSA has not been previously studied in Thai bus drivers. Both sleep quality and risk of OSA are essential considerations in maintaining the health and safety of employees. This cross-sectional study aimed to describe sleep quality and explore factors associated with poor sleep quality in intercity Thai bus drivers. We hypothesized that Thai intercity bus drivers would report poor sleep quality and that health problems, OSA risk, health behaviors, and working conditions would be associated factors.

\section{Materials and Methods}

\section{Study design and population}

This study employed a cross-sectional design. The study participants included 484 bus drivers from four bus transportation companies in Thailand. The sample size of this study was calculated based on the data from the previous research in which poor sleep quality was reported at $27.2 \%$ and was associated with five independent risk factors ${ }^{20)}$. With a power of 0.8 and level of significance of 0.05 , the total sample size was 440 participants: we aimed to enroll another $10 \%$ to compensate for missing data: finally, 484 participants were recruited into the study.

Seven bus transportation companies across Thailand were contacted, and four companies agreed to participate. A survey comprising three questionnaires was sent to these commercial bus transportation companies and questionnaires were distributed to bus drivers who met the inclusion criteria: (1) drive between cities (2) had been driving in the current company for at least one year, and (3) able to read the Thai language.

\section{Measurements}

Sleep quality

The Thai version of the Pittsburgh Sleep Quality Index (Thai-PSQI) was used to measure sleep quality ${ }^{24)}$. The PSQI assesses overall sleep quality over the previous month. It comprises 19 self-rated items categorized into seven components: sleep latency, sleep duration, sleep disturbances, habitual sleep efficiency, subjective sleep quality, use of sleep medications, and daytime dysfunction. Responses are recorded on a scale ranging from 0 to 3 , with 3 indicating the greatest dysfunction. Summing of the seven component scores yields one global sleep score ranging from 0 to 21 and the global scores greater than 5 indicate poor sleep quality ${ }^{24,25}$. In the study reporting the Thai version of the questionnaire, the Cronbach's alpha was 0.84 ; test-retest reliability was 0.89 ; the sensitivity for discriminating good sleepers from poor sleepers was $77.78 \%$, and the specificity for correctly classifying good sleepers was $93.33 \%{ }^{24)}$. In our study, a Cronbach's alpha of 0.72 was obtained for the questionnaire.

\section{Risk of sleep apnea}

The Thai version of the Berlin Questionnaire was used to measure the risk of sleep apnea ${ }^{26)}$. The questionnaire has ten items divided into three categories: (1) snoring, (2) wake time sleepiness and/or drowsy driving, and (3) history of hypertension or BMI >30 kilograms per square meter $\left(\mathrm{kg} / \mathrm{m}^{2}\right)$. If respondents are found to fall into at least two categories, they are defined as being at high risk of sleep apnea; those that fall into one or no category are defined as being at low risk. The Thai version had a reported Cronbach's alpha of 0.68 . Test-retest reliability was 0.97 . The sensitivity of the questionnaire was $87 \%$, and the 
specificity was $75 \%{ }^{26)}$. In our study, the Cronbach's alpha for the questionnaire was 0.79 . Permission was obtained for the use of the Thai version instruments.

Sociodemographic, lifestyle behaviors, and work data

We prepared a questionnaire to collect participant data on sociodemographic, lifestyle behaviors, and work characteristics. Sociodemographic variables included age, marital status, body mass index (BMI), health status, lifestyle behaviors, including alcohol and coffee consumption, smoking habits, use of energy drinks, and whether they exercised or not. BMI was calculated as weight divided by squared height $\left(\mathrm{kg} / \mathrm{m}^{2}\right)$. According to the WHO recommendation for Asian populations, participant BMIs were categorized into underweight $\left(<18.5 \mathrm{~kg} / \mathrm{m}^{2}\right)$, normal weight (18.5 to $22.9 \mathrm{~kg}$ / $\mathrm{m}^{2}$ ), overweight $\left(23-24.9 \mathrm{~kg} / \mathrm{m}^{2}\right)$, and obesity ( $\geq 25 \mathrm{~kg} /$ $\left.\mathrm{m}^{2}\right)^{27)}$. Regarding health status, participants were asked if they had any current health problems and if so, were asked to list these. Lastly, participants were asked about their work characteristics, including years of commercial bus driving, driving shift(s), a number of routes per day, driving hours per route, rest during driving, and having switching drivers.

\section{Data analysis}

Participant characteristics and sleep quality were described using descriptive statistics. Categorical data were presented as numbers and percentages. Univariate logistic regression was used to identify the relationship between each variable and sleep quality. The invested variables were demographic characteristics, health behaviors, working conditions, and risk of sleep apnea. The variables with $p$-values less than 0.25 and those with clinical significance were selected in multivariate logistic regression ${ }^{28)}$. Multivariate logistic regression using the enter method which all independent variables are entered into the equation at the same time was used to analyze factors related to low sleep quality. All variables included in the model are shown in the multivariate analysis table (Table 3). The Statistical Package for the Social Science (version 22, IBM SPSS Statistics) was used. A statistical significance level of $\alpha=0.05$ was adopted for the analyses.

\section{Ethics}

The study was approved by the Research Ethical Committee of the Faculty of Nursing, Chiang Mai University, Thailand (Ref: no. 142/2015). Surveys were given to each participant in sealed envelopes that also included an information sheet about the study and an informed consent form. Signed informed consent was obtained from all par- ticipants. We assured participants that confidentiality would be maintained and that no identifying information would be revealed in research reports or scientific publications.

\section{Results}

A total of 444 participants returned the survey along with written informed consent, with a response rate of $99.1 \%$. Among these surveys, 107 were excluded because of incomplete sleep quality responses that could not be the sum of the score to define good or poor sleep quality. Therefore, a total of 338 surveys were analyzed. All the bus drivers were male with a mean age of $45.8 \mathrm{yr}(\mathrm{SD}=8.1)$, and $73.6 \%$ were married. About $26 \%$ of participants reported having chronic health problems, and diabetes was the most prevalent, followed by hypertension. Participant means BMI was $25.6 \mathrm{~kg} / \mathrm{m}^{2}$ and $48.5 \%$ were defined as obese. Regarding lifestyle behaviors, $27.8 \%$ of the participants currently smoked, $91.6 \%$ consumed coffee, and 54.3\% used alcohol. About $18.1 \%$ of the bus drivers were found to be at high risk for sleep apnea. As for working conditions, $70.3 \%$ of the bus drivers worked rotating day or night driving shifts, and $40.3 \%$ reported driving at least $5 \mathrm{~h}$ per route.

The average sleep duration was $5.5 \mathrm{~h}(\mathrm{SD}=1.8)$, and $33.4 \%$ had less than $5 \mathrm{~h}$ of sleep. Sleep latency of between 16 and $30 \mathrm{~min}$ was reported by $53.2 \%$ of participants, and $37.5 \%$ had habitual sleep efficiency of less than $65 \%$. However, $58.1 \%$ reported that their sleep was reasonably good. About $12.7 \%$ used sleep medications in the previous month and results from the global PSQI score indicated that $65.7 \%$ of the bus drivers had poor sleep quality (PSQI scores $>5$ ) (Table 1).

Table 2 presents the univariate logistic regression. The variables included age, marital status, educational level, BMI, health status, smoking, alcohol use, caffeine consumption, use of energy drinks, exercise, years of company driving experience, driving shift(s), total driving hour per day, rest during driving, having switching drivers, and risk of sleep apnea. The analysis showed an increased risk of poor sleep quality for variables related to marital status, years of driving experience, driving shifts, and switching drivers during a route.

In multivariate analysis, variables were entered to explore potential risk factors for low sleep quality and the results showed that married status $(\mathrm{OR}=3.1,95 \%$ $\mathrm{CI}=1.2-8.2)$, alcohol consumption $(\mathrm{OR}=2.7,95 \% \mathrm{CI}=1.3-$ 5.6), no exercise ( $\mathrm{OR}=2.3,95 \% \mathrm{CI}=1.1-4.9)$, night driving shift $(\mathrm{OR}=20.6,95 \% \mathrm{CI}=4.9-87.3)$, and rotating day or night driving shift $(\mathrm{OR}=17.0,95 \% \mathrm{CI}=5.1-56.6)$, were 
Table 1. Sleep quality of bus drivers

\begin{tabular}{|c|c|c|c|}
\hline PSQI items & $\mathrm{n}$ & $\%$ & Mean (SD) \\
\hline Sleep latency $(\mathrm{min})(\mathrm{N}=316)$ & & & $20.4(15.9)$ \\
\hline$\leq 15$ & 71 & 22.5 & \\
\hline $16-30$ & 168 & 53.2 & \\
\hline $31-60$ & 69 & 21.8 & \\
\hline$>60$ & 8 & 2.5 & \\
\hline Sleep duration $(\mathrm{h})(\mathrm{N}=335)$ & & & $5.5(1.8)$ \\
\hline$>7$ & 66 & 19.7 & \\
\hline $6-7$ & 34 & 10.2 & \\
\hline $5-6$ & 123 & 36.7 & \\
\hline$<5$ & 112 & 33.4 & \\
\hline Sleep efficiency (\%) (N=283) & & & $74.8(27.54)$ \\
\hline$\geq 85$ & 88 & 31.1 & \\
\hline $75-84$ & 51 & 18 & \\
\hline $65-74$ & 38 & 13.4 & \\
\hline$<65$ & 106 & 37.5 & \\
\hline \multicolumn{4}{|l|}{ Subjective sleep quality $(\mathrm{N}=334)$} \\
\hline Very good & 88 & 26.3 & \\
\hline Fairly good & 194 & 58.1 & \\
\hline Fairly bad & 51 & 15.3 & \\
\hline Very bad & 1 & 0.3 & \\
\hline \multicolumn{4}{|c|}{ Use of sleeping medication $(\mathrm{N}=331)$} \\
\hline Never & 289 & 87.3 & \\
\hline Use less than once a week & 33 & 10 & \\
\hline Use more than once a week & 9 & 2.7 & \\
\hline \multicolumn{4}{|l|}{ Global PSQI scores $(\mathrm{N}=338)$} \\
\hline Poor sleepers (PSQI >5) & 222 & 65.7 & \\
\hline Good sleepers (PSQI $\leq 5)$ & 116 & 34.3 & \\
\hline
\end{tabular}

PSQI: Pittsburgh Sleep Quality Index.

related to poor sleep quality (Table 3 ).

\section{Discussion}

In line with our hypothesis that bus drivers would report poor sleep quality, nearly $66 \%$ of bus drivers did. The high rates of poor sleep quality raise obvious concerns for public and passenger safety. This result was comparable to a Buenos Aires study which reported that $66.7 \%$ of bus drivers suffered from poor sleep quality ${ }^{10)}$ but much higher than that reported by general adult drivers in Korea $(21 \%)^{29)}$. It is likely that bus drivers had poorer sleep quality than drivers in general because of the working conditions such as shift work. In addition, the mean sleep duration reported by bus drivers in our study was $5.5 \mathrm{~h}$, considerably less than that reported by bus drivers in other countries which ranged from 6.2 to $6.7 \mathrm{~h}^{10,18,30)}$.

In regard to factors associated with poor sleep quality, alcohol consumption was reported by $54.3 \%$ of bus drivers, of those consuming alcohol, $11 \%$ reported consuming alcohol daily. Drivers who consumed alcohol were more likely to report poorer sleep quality than those who did not. This result was in line with that of Park et al. ${ }^{31)}$, who stated that alcohol use was significantly associated with some PSQI components - namely, subjective sleep quality, sleep duration, and sleep disturbance - in the Korean general population. The poor quality of sleep associated with alcohol consumption is perhaps due to the tendency for alcohol to briefly increase sleepiness but later cause frequent wakening and early morning wakening ${ }^{32}$. The high rate of alcohol consumption in our study suggests that bus companies need to develop prevention programs and that legislation regarding drink driving should be strictly enforced.

In our study, bus drivers who reported not exercising showed a high risk for poor sleep quality. A recent systematic review and meta-analysis from six trails confirmed that exercise could improve sleep quality ${ }^{33)}$. It has been known that exercise enhances sleep through increasing energy consumption, endorphin secretion, and body temperature which can facilitate the sleep process ${ }^{34,35)}$. However, bus drivers' irregular work schedules are an obstacle to establishing a regular exercise regimen and $34.4 \%$ of bus drivers in our study reported not exercising.

Regarding working conditions, our analysis confirmed that bus drivers working night shifts and a rotating day or night shifts were more likely to have poor sleep quality than drivers' working day shifts alone. However, the confidence intervals in this analysis were relatively wide because relatively few participants worked day shifts. Intercity Thai buses are commonly timetabled to operate overnight to avoid traffic and avoid delays and this disrupts drivers' normal circadian rhythms. Previous studies have also found that truck drivers with irregular schedules slept less and experienced more sleep disruption than those with fixed work shifts ${ }^{36}$. It seems clear that bus drivers working rotating shifts accumulate sleep debt and fatigue due to working at night ${ }^{37)}$. In addition, sleep structure is affected when sleep occurs during the day after working at night. The changes in sleep structure take the form of increased REM sleep latency, a decreased percentage of REM sleep ${ }^{38)}$, reduced sleep duration, and reduced sleep efficiency ${ }^{39)}$. Moreover, daytime sleeping results in misalignment of the circadian rhythm because melatonin secretion decreases and core body temperature increases during the day, and both impair sleep quality ${ }^{37)}$.

The risk of OSA showed a moderate prevalence (18.1\%). This prevalence was slightly lower than that found in truck drivers in Belgium $(21.5 \%)^{20)}$ and Iran $(24.8 \%)^{19)}$ but 
Table 2. Association between poor sleep quality and potential risk factors using univariate logistic regression

\begin{tabular}{|c|c|c|c|c|c|c|}
\hline \multirow{2}{*}{ Characteristics } & \multirow{2}{*}{$\begin{array}{l}\text { Number of } \\
\text { respondents }\end{array}$} & \multicolumn{5}{|c|}{ Drivers with poor sleep quality } \\
\hline & & $\mathrm{n}$ & $\%$ & OR & $95 \% \mathrm{CI}$ & $p$-value \\
\hline Age (yr) $(\mathrm{N}=329)$ & & & & & & 0.143 \\
\hline$<40$ & 83 & 49 & 59.1 & ref & & \\
\hline$\geq 40$ & 246 & 167 & 67.9 & 0.68 & $0.41-1.14$ & \\
\hline Marital status $(\mathrm{N}=329)$ & & & & & & $0.037^{*}$ \\
\hline Single & 50 & 25 & 50 & ref & & \\
\hline Married & 242 & 164 & 67.8 & 2.1 & $1.14-3.90$ & \\
\hline Divorced/separated & 37 & 27 & 73 & 2.7 & $1.08-6.73$ & \\
\hline Level of education $(\mathrm{N}=333)$ & & & & & & 0.11 \\
\hline Higher than primary school & 103 & 61 & 59.2 & ref & & \\
\hline Primary school & 230 & 157 & 68.3 & 0.68 & $0.42-1.09$ & \\
\hline Health problems $(\mathrm{N}=322)$ & & & & & & 0.733 \\
\hline No & 240 & 156 & 65 & ref & & \\
\hline Yes & 82 & 55 & 62.5 & 1.1 & $0.65-1.87$ & \\
\hline $\operatorname{BMI}\left(\mathrm{kg} / \mathrm{m}^{2}\right) \quad(\mathrm{N}=326)$ & & & & & & 0.114 \\
\hline$\leq 22.9$ & 94 & 54 & 57.4 & ref & & \\
\hline $23-24.9$ & 74 & 54 & 73 & 2 & $1.04-3.85$ & \\
\hline$\geq 25$ & 158 & 103 & 65.2 & 1.39 & $0.822-2.34$ & \\
\hline Smoking habits $(\mathrm{N}=338)$ & & & & & & 0.968 \\
\hline No smoking & 176 & 115 & 65.3 & ref & & \\
\hline Used to smoke & 68 & 45 & 66.2 & 1.07 & $0.59-1.93$ & \\
\hline Current smoking & 94 & 62 & 66 & 1.06 & $0.62-1.79$ & \\
\hline Coffee consumption $(\mathrm{N}=335)$ & & & & & & 0.525 \\
\hline No & 28 & 20 & 71.4 & ref & & \\
\hline Yes & 307 & 201 & 65.4 & 0.76 & $0.32-1.78$ & \\
\hline Alcohol consumption $(\mathrm{N}=335)$ & & & & & & 0.301 \\
\hline No & 153 & 96 & 62.7 & ref & & \\
\hline Yes & 182 & 124 & 68.1 & 1.27 & $0.81-1.99$ & \\
\hline Use of energy drinks $(\mathrm{N}=333)$ & & & & & & 0.144 \\
\hline No & 86 & 51 & 59.3 & ref & & \\
\hline Yes & 247 & 168 & 68 & 1.46 & $0.88-2.42$ & \\
\hline Exercise $(\mathrm{N}=326)$ & & & & & & 0.095 \\
\hline Yes & 214 & 135 & 63.1 & ref & & \\
\hline No & 112 & 81 & 72.3 & 1.53 & $0.93-2.52$ & \\
\hline Risk of OSA $(\mathrm{N}=320)$ & & & & & & 0.148 \\
\hline No & 262 & 168 & 64 & ref & & \\
\hline Yes & 58 & 43 & 74.1 & 1.6 & $0.85-3.04$ & \\
\hline Years of bus driving $(\mathrm{N}=317)$ & & & & & & $0.003^{* *}$ \\
\hline$>10 \mathrm{yr}$ & 165 & 95 & 57.6 & ref & & \\
\hline$\leq 10 \mathrm{yr}$ & 152 & 112 & 73.7 & 0.49 & $0.30-0.78$ & \\
\hline Driving shift(s) $(\mathrm{N}=333)$ & & & & & & $0.000 * *$ \\
\hline Day only & 41 & 7 & 17.1 & ref & & \\
\hline Night only & 58 & 43 & 74.1 & 13.92 & $5.10-37.99$ & \\
\hline Day or night & 234 & 167 & 71.4 & 12.11 & $5.12-28.65$ & \\
\hline Driving hours per/route $(\mathrm{N}=288)$ & & & & & & 0.786 \\
\hline$<5 \mathrm{~h}$ & 172 & 110 & 64 & ref & & \\
\hline$\geq 5 \mathrm{~h}$ & 116 & 76 & 65.5 & 1.07 & $0.654-1.75$ & \\
\hline Rest period during each route $(\mathrm{N}=334)$ & & & & & & 0.518 \\
\hline Yes & 274 & 181 & 66.1 & ref & & \\
\hline No & 60 & 37 & 61.7 & 0.83 & $0.46-1.47$ & \\
\hline Switching of drivers during routes $(\mathrm{N}=334)$ & & & & & & $0.000 * *$ \\
\hline Yes & 265 & 189 & 71.3 & ref & & \\
\hline No & 69 & 29 & 42 & 0.29 & $0.17-0.50$ & \\
\hline Number of routes per day $(\mathrm{N}=300)$ & & & & & & 0.164 \\
\hline 1 ride & 203 & 138 & 68 & ref & & \\
\hline$>1$ ride & 97 & 58 & 59.8 & 0.70 & $0.42-1.16$ & \\
\hline
\end{tabular}

${ }^{*} p<0.05,{ }^{* *} p<0.01$, OR: Odds Ratio; CI: Confidence Interval; BMI: Body mass index; OSA: Obstructive sleep apnea. 
Table 3. Multivariate logistic regression analysis of factors related to poor sleep quality

\begin{tabular}{lcl}
\hline Variable & OR (95\% CI) & $p$-value \\
\hline Age (<40 vs. $\geq 40$ (ref)) & $1.24(0.51-3.01)$ & 0.631 \\
Marital status (single (ref), married, divorced/separated) & & \\
$\quad$ Married & $3.11(1.18-8.19)$ & $0.022^{*}$ \\
$\quad$ Divorced/separated & $2.22(0.63-7.81)$ & 0.214 \\
Level of education (higher than primary school vs. primary school (ref)) & $0.67(0.31-1.44)$ & 0.302 \\
Health problems (no (ref) vs. yes) & $0.49(0.20-1.17)$ & 0.106 \\
BMI ( $\leq 22.9$ (ref), 23-24.9, $\geq 25)$ & & \\
$23-24.9$ & $1.99(0.73-5.40)$ & 0.177 \\
$\quad \geq 25$ & $0.76(0.33-1.73)$ & 0.51 \\
Smoking habits (no (ref), used to, current) & & \\
$\quad$ Used to smoke & $1.65(0.66-4.16)$ & 0.286 \\
$\quad$ Current smoke & $1.09(0.48-2.51)$ & 0.83 \\
Coffee consumption (yes vs. no (ref)) & $0.57(0.18-1.86)$ & 0.352 \\
Alcohol consumption (yes vs. no (ref)) & $2.71(1.31-5.58)$ & $0.007^{* *}$ \\
Use of energy drinks (yes vs. no (ref)) & $1.24(0.57-2.70)$ & 0.58 \\
Exercise (no vs. yes (ref)) & $2.29(1.07-4.88)$ & $0.033^{*}$ \\
Risk of OSA (yes vs. no (ref)) & $1.15(0.43-3.06)$ & 0.783 \\
Years of bus driving ( $>10$ yr (ref) vs. $\leq 10$ yr) & $0.45(0.20-1.00)$ & 0.05 \\
Driving shift(s) (day (ref), night, day or night) & & \\
$\quad$ Night only & $20.63(4.88-87.25)$ & $0.000^{* *}$ \\
Day or night & $17.04(5.13-56.56)$ & $0.000^{* *}$ \\
Driving hours per/route $(\geq 5$ h vs. $<5$ h (ref)) & $0.81(0.39-1.72)$ & 0.59 \\
Rest period during each route (no vs. yes (ref)) & $0.78(0.32-1.90)$ & 0.588 \\
Switching of drivers during routes (no vs. yes (ref)) & $2.45(0.98-6.17)$ & 0.057 \\
Number of routes per day (1 ride (ref) vs. $>1$ ride) & $1.33(0.62-2.86)$ & 0.461 \\
\hline
\end{tabular}

${ }^{*} p<0.05,{ }^{* *} p<0.01$, dependent variable: sleep quality (poor and good sleep quality).

OR: Odds ratio; CI: Confidence interval; BMI: Body mass index; OSA Obstructive sleep apnea.

higher than that found in drivers in Saudi Arabia $(11.3 \%)^{18)}$. It is evident that OSA risk is prevalent in truck and bus drivers. Variations in OSA risk prevalence seen across studies are common due to population differences as well as variations in methods used to measure sleep apnea such as using a risk questionnaire or polysomnography. In our study, we found no significant relationship between risks of OSA and sleep quality perhaps because the majority of bus drivers showed a low risk of OSA (81.9\%), and that other factors such as working conditions may have a greater influence on sleep quality. Further studies should be performed to more thoroughly examine the potential relationship between OSA risks and sleep quality.

Demographic characteristics such as age, BMI, and health problems were not significantly related to poor sleep quality in our study. This lack of association between age, health problems, and poor sleep quality may be explained by the low rate of reported health problems $(25.5 \%)$ in our study and other factors may account for poor sleep quality rather than age itself. In previous studies, BMI was found to be related to daytime sleepiness ${ }^{40)}$ and risk of OSA ${ }^{41)}$, but there is a lack of data on the relationship to sleep quality in this study. It is likely that a number of physical and mental health factors, other than age, affect sleep quality in older individuals.

Although there are no restrictions on women becoming drivers in Thailand, there is a perception that men are better drivers and that driving buses between cities are a job for males with women required to be responsible for the family. Few previous studies have compared the health, well-being and psychophysiological differences between male and female bus drivers but results suggest that no gender differences exist on occupational stressors ${ }^{42)}$. Female and males both had higher levels of stress hormone and, while at work, self-reported distress and mood were similar for both genders ${ }^{43}$.

\section{Conclusion}

The study results indicate a high prevalence of poor 
sleep quality among Thai bus drivers. Related factors for poor sleep quality are alcohol consumption and shift working conditions, but exercise showed a protective effect. Although the risk of OSA was not statistically significantly associated with poor sleep quality, the number of bus drivers with a high risk of OSA reporting poor sleep quality were higher than those reporting good sleep quality. Besides, many bus drivers were overweight and obese which can increase the risk of OSA. Serious consideration of implementing screening for OSA among commercial drivers is required to decrease drowsy driving and traffic accidents. Our study had some limitations. Bias from selfreported data may occur particularly around topics that are threatening or sensitive such as substance use. The low internal consistency of the Thai version questionnaire among bus drivers may be attributable to the nature of working conditions. Irregular shift working patterns and subsequent sleep schedules making recall of sleep patterns problematic. Although there was a large sample size included, some bus transportation companies refused to participate and it is not known if working conditions are comparable with those included in the study, this may limit the generalizability of the study. However, this was the first study to study sleep quality and potential risk factors including risk for sleep apnea among bus drivers in Thailand. The results suggest that education on healthy lifestyles is needed for both bus drivers and the transportation companies. Importantly, exercise should be promoted in the workplaces and education on harmful to alcohol use. Health screening programs should be provided for all bus drivers at times they can attend especially those at risk for OSA and metabolic syndrome. Future studies should include information about the company's work organization and policies that may impact on bus drivers' performance and health.

\section{Conflicts of Interest}

The authors declare that they have no conflict of interests.

\section{Funding}

The study was supported by a research grant from Chiang Mai University.

\section{Acknowledgements}

The authors would like to thank all participants for their time and dedication to the study. Special thanks to Prof. Teresa Stone for suggestions and comments on the manuscript and Mr. Jon Mann, UIC Academic Center for Excellence, for editing an English writing.

\section{References}

1) de Mello MT, Narciso FV, Tufik S, Paiva T, Spence DW, Bahammam AS, Verster JC, Pandi-Perumal SR (2013) Sleep disorders as a cause of motor vehicle collisions. Int $\mathrm{J}$ Prev Med 4, 246-57. [Medline]

2) Useche SA, Ortiz VG, Cendales BE (2017) Stress-related psychosocial factors at work, fatigue, and risky driving behavior in bus rapid transport (BRT) drivers. Accid Anal Prev 104, 106-14. [Medline] [CrossRef]

3) Phatrabuddha N, Yingratanasuk T, Rotwannasin P, Jaidee W, Krajaiklang N (2018) Assessment of sleep deprivation and fatigue among chemical transportation drivers in Chonburi, Thailand. Saf Health Work 9, 159-63. [Medline] [CrossRef]

4) Watson NF, Morgenthaler T, Chervin R, Carden K, Kirsch D, Kristo D, Malhotra R, Martin J, Ramar K, Rosen I, Weaver T Wise M, American Academy of Sleep Medicine Board of Directors (2015) Confronting drowsy driving: The American Academy of Sleep Medicine perspective. J Clin Sleep Med 11, 1335-6. [Medline] [CrossRef]

5) Taylor AH, Dorn L (2006) Stress, fatigue, health, and risk of road traffic accidents among professional drivers: the contribution of physical inactivity. Annu Rev Public Health 27, 371-91. [Medline] [CrossRef]

6) Kee S, Tamrin SBM, Meng YG (2010) Driving fatigue and performance among occupational drivers in simulated prolonged driving. Glob J Health Sci 2, 167-77.

7) Higgins JS, Michael J, Austin R, Åkerstedt T, Van Dongen HP, Watson N, Czeisler C, Pack AI, Rosekind MR (2017) Asleep at the wheel-the road to addressing drowsy driving. Sleep 40. [Medline] [CrossRef]

8) Mello MT, Santana MG, Souza LM, Oliveira PC, Ventura ML, Stampi C, Tufik S (2000) Sleep patterns and sleeprelated complaints of Brazilian interstate bus drivers. Braz $\mathrm{J}$ Med Biol Res 33, 71-7. [Medline] [CrossRef]

9) Anund A, Ihlström J, Fors C, Kecklund G, Filtness A (2016) Factors associated with self-reported driver sleepiness and incidents in city bus drivers. Ind Health 54, 337-46. [Medline] [CrossRef]

10) Diez JJ, Vigo DE, Lloret SP, Rigters S, Role N, Cardinali DP, Chada DP (2011) Sleep habits, alertness, cortisol levels, and cardiac autonomic activity in short-distance bus drivers: differences between morning and afternoon shifts. J Occup Environ Med 53, 806-11. [Medline] [CrossRef]

11) Kingshott RN, Cowan JO, Jones DR, Flannery EM, Smith AD, Herbison GP, Taylor DR (2004) The role of sleepdisordered breathing, daytime sleepiness, and impaired performance in motor vehicle crashes-a case control study. Sleep Breath 8, 61-72. [Medline]

12) Ozer C, Etcibaşı S, Oztürk L (2014) Daytime sleepiness and sleep habits as risk factors of traffic accidents in a group of Turkish public transport drivers. Int J Clin Exp Med 7, 268-73. [Medline]

13) Bener A, Yildirim E, Özkan T, Lajunen T (2017) Driver 
sleepiness, fatigue, careless behavior and risk of motor vehicle crash and injury: population based case and control study. J Traffic Transp Eng 4, 496-502.

14) Deza-Becerra F, Rey de Castro J, Gonzales-Gonzales C, León-Jiménez FE, Osada-Liy J, Rosales-Mayor E (2017) Sleep habits, fatigue, and sleepiness in Chiclayo-Peru's bus drivers. Sleep Breath 21, 745-9. [Medline] [CrossRef]

15) Kwamru J (2005) Selected factors related to sleepiness among bus drivers. Chulalongkorn University, Bangkok.

16) Leechawengwongs M, Leechawengwongs E, Sukying C, Udomsubpayakul U (2006) Role of drowsy driving in traffic accidents: a questionnaire survey of Thai commercial bus/truck drivers. J Med Assoc Thai 89, 1845-50. [Medline]

17) Razmpa E, Sadegh Niat K, Saedi B (2011) Urban bus drivers' sleep problems and crash accidents. Indian J Otolaryngol Head Neck Surg 63, 269-73. [Medline] [CrossRef]

18) BaHammam AS, Alkhunizan MA, Lesloum RH, Alshanqiti AM, Aldakhil AM, Pandi-Perumal SR, Sharif MM (2014) Prevalence of sleep-related accidents among drivers in Saudi Arabia. Ann Thorac Med 9, 236-41. [Medline] [CrossRef]

19) Ebrahimi MH, Sadeghi M, Dehghani M, Niiat KS (2015) Sleep habits and road traffic accident risk for Iranian occupational drivers. Int J Occup Med Environ Health 28, 305-12. [Medline]

20) Braeckman L, Verpraet R, Van Risseghem M, Pevernagie D, De Bacquer D (2011) Prevalence and correlates of poor sleep quality and daytime sleepiness in Belgian truck drivers. Chronobiol Int 28, 126-34. [Medline] [CrossRef]

21) Vennelle M, Engleman HM, Douglas NJ (2010) Sleepiness and sleep-related accidents in commercial bus drivers. Sleep Breath 14, 39-42. [Medline] [CrossRef]

22) Sadeghniiat-Haghighi K, Yazdi Z, Kazemifar AM (2016) Sleep quality in long haul truck drivers: a study on Iranian national data. Chin J Traumatol 19, 225-8. [Medline] [CrossRef]

23) World Health Organization Thailand. Strengthening road safety in Thailand 2016 http://www.searo.who.int/thailand/ areas/roadsafety/en/.

24) Sitasuwan T, Bussaratid S, Ruttanaumpawan P, Chotinaiwattarakul W (2014) Reliability and validity of the Thai version of the Pittsburgh Sleep Quality Index. J Med Assoc Thai 97 Suppl 3, S57-67. [Medline]

25) Buysse DJ, Reynolds CF 3rd, Monk TH, Berman SR, Kupfer DJ (1989) The Pittsburgh Sleep Quality Index: a new instrument for psychiatric practice and research. Psychiatry Res 28, 193-213. [Medline] [CrossRef]

26) Suksakorn S, Rattanaumpawan $P$, Banhiran W, Cherakul N, Chotinaiwattarakul W (2014) Reliability and validity of a Thai version of the Berlin questionnaire in patients with sleep disordered breathing. J Med Assoc Thai 97 Suppl 3, S46-56. [Medline]

27) WHO Expert Consultation (2004) Appropriate body-mass index for Asian populations and its implications for policy and intervention strategies. Lancet 363, 157-63. [Medline] [CrossRef]

28) Hosmer DW, Lemeshow S (1989) Applied logistic regression. Wiley, New York.

29) Sunwoo JS, Hwangbo Y, Kim WJ, Chu MK, Yun CH, Yang KI (2017) Sleep characteristics associated with drowsy driving. Sleep Med 40, 4-10. [Medline] [CrossRef]

30) Hui DS, Chan JK, Ko FW, Choy DK, Li TS, Chan AT, Wong KK, Lai CK (2002) Prevalence of snoring and sleepdisordered breathing in a group of commercial bus drivers in Hong Kong. Intern Med J 32, 149-57. [Medline] [CrossRef]

31) Park SY, Oh MK, Lee BS, Kim HG, Lee WJ, Lee JH, Lim JT, Kim JY (2015) The effects of alcohol on quality of sleep. Korean J Fam Med 36, 294-9. [Medline] [CrossRef]

32) Ebrahim IO, Shapiro CM, Williams AJ, Fenwick PB (2013) Alcohol and sleep I: effects on normal sleep. Alcohol Clin Exp Res 37, 539-49. [Medline] [CrossRef]

33) Banno M, Harada Y, Taniguchi M, Tobita R, Tsujimoto H, Tsujimoto Y, Kataoka Y, Noda A (2018) Exercise can improve sleep quality: a systematic review and metaanalysis. PeerJ 6, e5172. [Medline] [CrossRef]

34) Driver HS, Taylor SR (2000) Exercise and sleep. Sleep Med Rev 4, 387-402. [Medline] [CrossRef]

35) Li F, Fisher KJ, Harmer P, Irbe D, Tearse RG, Weimer C (2004) Tai chi and self-rated quality of sleep and daytime sleepiness in older adults: a randomized controlled trial. J Am Geriatr Soc 52, 892-900. [Medline] [CrossRef]

36) Moreno CR, Louzada FM, Teixeira LR, Borges F, LorenziFilho G (2006) Short sleep is associated with obesity among truck drivers. Chronobiol Int 23, 1295-303. [Medline] [CrossRef]

37) Santos EH, de Mello MT, Pradella-Hallinan M, Luchesi L, Pires ML, Tufik S (2004) Sleep and sleepiness among Brazilian shift-working bus drivers. Chronobiol Int 21, 881-8. [Medline] [CrossRef]

38) Narciso FV, Esteves AM, Oliveira e Silva L, Bittencourt LR, Silva RS, Pires ML, Tufik S, de Mello MT (2013) Do circadian preferences influence the sleep patterns of night shift drivers? Med Princ Pract 22, 571-5. [Medline] [CrossRef]

39) Pires ML, Teixeira CW, Esteves AM, Bittencourt LR, Silva RS, Santos RF, Tufik S, Mello MT (2009) Sleep, ageing and night work. Braz J Med Biol Res 42, 839-43. [Medline] [CrossRef]

40) Giahi O, Khoubi J, Amiri M (2016) The association between insomnia and cardiovascular risk factors in bus drivers in Iran. Work 55, 207-14. [Medline] [CrossRef]

41) Xie W, Chakrabarty S, Levine R, Johnson R, Talmage JB (2011) Factors associated with obstructive sleep apnea among commercial motor vehicle drivers. J Occup Environ Med 53, 169-73. [Medline] [CrossRef]

42) Rydstedt LW, Johansson G, Evans GW (1998) A longitudinal study of workload, health and well-being among male and female urban bus drivers. J Occup Organ Psychol 71, 35-45. [CrossRef]

43) Aronsson G, Rissler A (1998) Psychophysiological stress reactions in female and male urban bus drivers. J Occup Health Psychol 3, 122-9. [Medline] [CrossRef] 